\title{
Short-Term Synaptic Plasticity Contributes to the Temporal Filtering of Electrosensory Information
}

\author{
Eric S. Fortune and Gary J. Rose \\ Department of Biology, University of Utah, Salt Lake City, Utah 84112-0840
}

\begin{abstract}
Short-term synaptic depression and facilitation often are elicited by different temporal patterns of activity. Short-term plasticity may contribute, therefore, to temporal filtering by impeding synaptic transmission for some temporal patterns of activity and facilitating transmission for other patterns. We examined this hypothesis by investigating whether short-term plasticity contributes to the temporal filtering properties of midbrain electrosensory neurons. Postsynaptic potentials were recorded in response to sensory stimuli and to direct stimulation of afferents, in vivo. Stimulating afferents with pairs of pulses at a rate of 20 pairs/sec ["tetanus $(20 \mathrm{~Hz})$ "] induced PSP depression. This PSP depression was similar to that observed for electrosensory stimuli of the same temporal frequency. Analysis of PSPs elicited by a pair of pulses that preceded versus followed the tetanus revealed that PSP depression was caused by synaptic depression, not by a loss of facilitation. Behavioral studies indicate that fish can de-
\end{abstract}

Synaptic plasticity is an increase or decrease in the efficacy of synaptic transmission with use. Increases or decreases in efficacy that occur over tens of milliseconds are referred to as facilitation and short-term depression, respectively (Zucker, 1989, 1999).

Although short-term synaptic plasticity appears to be widespread in nervous systems and across taxa, comparatively little is known concerning its function in neural circuits and behavior. Depression can be linked to habituation of the gill withdrawal reflex in Aplysia (Castellucci and Kandel, 1974) and escape-related reflexes in fish, crayfish, and insects. Facilitation has been related to the dishabituation of reflexes of this type. The ubiquity of short-term plasticity in other types of circuits, however, suggests that other roles are likely.

Short-term synaptic depression and facilitation at particular synapses are often elicited by different temporal patterns of activity. This differential frequency dependence can, therefore, contribute to translating different temporal patterns of activity into differing amplitudes of postsynaptic responses, i.e., temporal filtering (Lisman, 1997; Zador and Dobrunz, 1997; Dittman et al., 2000). The contribution of the interplay between synaptic depression and facilitation to the temporal filtering of information, in vivo, is presently unclear.

The electrosensory system of weakly electric fish has proven to be useful for investigating the functional relevance of synaptic plasticity (Berman et al., 1997; Bastian, 1998). These fish view the world through a temporal filter; slowly varying patterns of afferent activity are passed and amplified but repetitive, fast patterns are rejected (Partridge et al., 1981). These repetitive, fast patterns result from the interference of a fish's own electric organ discharges (EODs) with those of a neighbor; if too close in frequency,

\footnotetext{
Received March 20, 2000; revised July 5, 2000; accepted July 6, 2000.

This work was supported by National Science Foundation Grant IBN-91156789 and National Institutes of Health Fellowship 1-F32 NS 09779. We also thank G. J. Willden for histological assistance.

Correspondence should be addressed to Dr. Eric S. Fortune, Department of Biology, University of Utah, 257 South, 1400 East, Salt Lake City, UT 84112-0840. E-mail: eric@cooter.biology.utah.edu.

Copyright (C) 2000 Society for Neuroscience $0270-6474 / 00 / 207122-09 \$ 15.00 / 0$
}

tect slow changes in signal amplitude (slow AM) in backgrounds of fast fluctuations. Correspondingly, midbrain neurons respond well to slow AM even in the presence of fast AM. In many neurons, facilitation enhanced responses to trains (8-10 pulses; $100 \mathrm{~Hz}$ ) that represented activity patterns elicited by slow AM, despite induction of synaptic depression by a tetanus $(20 \mathrm{~Hz})$. The interplay between synaptic depression and facilitation, therefore, can act as a filter of temporal information. Some neurons that showed little facilitation nonetheless responded to low temporal-frequency information after induction of depression by fast information; this likely results from the convergence of inputs with different temporal filtering properties.

Key words: whole-cell patch; sensory processing; synaptic depression; facilitation; jamming avoidance response; in vivo; midbrain; intracellular fish shift their EOD frequencies in opposite directions to increase the frequency difference and hence the rate at which the two signals "beat." Passive and active membrane properties of neurons in the midbrain contribute to this filtering (Fortune and Rose, 1997b). In many cases, however, frequency-dependent depression of PSP amplitude plays a dominant role in the low-pass temporal filtering characteristics of midbrain neurons; for a sensory stimulus that has a periodicity of $20 \mathrm{~Hz}$ (e.g., beat rate of $20 \mathrm{~Hz}$ ), PSP amplitude can decline as much as 10 -fold over $1 \mathrm{sec}$ of stimulation (Rose and Fortune, 1999).

The mechanisms that underlie this frequency-dependent depression of PSP amplitude are unknown. The decline in PSP amplitude over time could, theoretically, result from synaptic depression, a loss of facilitation, or both. To discriminate between these possibilities, toral afferents from the electrosensory lateral line lobe (ELL) were stimulated directly via electrodes in the lateral lemniscus, in vivo, while recording intracellularly from neurons in the torus. We show that the decline in PSP amplitude with repetitive stimulation is caused by synaptic depression. We also show that this synaptic depression, paradoxically, does not necessarily preclude response to patterns of afferent activity that reflect low temporalfrequency components in a sensory stimulus, e.g., a firing rate of $\sim 80-100$ spikes/sec for $50-100 \mathrm{msec}$. The robust responses of neurons to these stimuli, despite synaptic depression, stem from synaptic facilitation in the torus and "network" properties.

\section{MATERIALS AND METHODS}

Experimental procedures were similar to those described previously (Heiligenberg and Rose, 1985; Rose and Call, 1993; Fortune and Rose, 1997a,b; Rose and Fortune, 1999). Fish, 1 year old, of the genus Eigenmannia were used. Animal husbandry, anesthesia, and surgical procedures were performed under the guidelines established by the Society for Neuroscience.

For experiments, a fish's EOD was measured and then attenuated ( $\sim 1000$-fold) by intramuscular injection of Flaxedil $(4 \mu \mathrm{g} / \mathrm{gm}$ of fish). Additional injections of Flaxedil were made during the experiment as necessary to maintain the attenuation of the EOD. The fish's EOD was replaced by a sinusoidal mimic (S1) that was delivered through electrodes placed at the tail and in the mouth. The amplitude and frequency of the S1 were adjusted to approximate the fish's EOD before the injection of Flaxedil. Additional electrosensory stimuli were delivered through an 
array of carbon electrodes that surrounded the fish. Water temperature was held near $25^{\circ} \mathrm{C}$.

At the conclusion of the experiment, not $>4 \mathrm{hr}$ after the first neuron was filled, animals were deeply anesthetized by a flow of $2 \%(\mathrm{w} / \mathrm{v})$ urethane across the gills. Animals were perfused transcardially with saline-heparin solution followed by $4 \%(\mathrm{w} / \mathrm{v})$ paraformaldehyde in $0.2 \mathrm{M}$ phosphate buffer $\mathrm{pH}$ 7.4. After perfusion, the brain was removed and stored at $4^{\circ} \mathrm{C}$ overnight in the paraformaldehyde solution. Sections, $100 \mu \mathrm{m}$ thick, were cut on a vibratome and reacted using an avidin-biotin peroxidase kit (Vector Laboratories, Burlingame, CA). Sections were dehydrated, cleared in xylenes, mounted on slides, and coverslipped. Stereotrode tracks were easily recognized and confirmed placement in the lateral lemniscus.

Placement of stimulating electrodes. Paired tungsten stereotrodes (World Precision Instruments, Sarasota, FL) were placed into the lateral lemniscus (LL), 200-300 $\mu \mathrm{m}$ caudal of the region where intracellular recordings were made (Fig. 1 $A$ ). For placement, differential recordings were made while advancing the stereotrodes to a depth between 1200 and $1600 \mu \mathrm{m}$. The LL was detected by recording strong multiunit activity in response to an ongoing $4 \mathrm{~Hz}$ beat stimulus.

Intracellular recording procedures. Whole-cell recordings were made with patch-type pipettes, as described in detail by Rose and Fortune (1996). Seal resistances of $1 \mathrm{G} \Omega$ or more were typically achieved. Intracellular recordings were made from neurons in the dorsal 5 layers of the torus semicircularis of adult Eigenmannia. Patch pipettes for intracellular recording were constructed from borosilicate capillary glass (A-M systems \#5960; $1 \mathrm{~mm}$ outer diameter; $0.58 \mathrm{~mm}$ inner diameter) using a FlamingBrown type puller (model P-97; Sutter Instruments). Electrodes were pulled to resistances between 15 and $25 \mathrm{M} \Omega$. Electrode tips were backfilled with a solution ( $\mathrm{pH} 7.4 ; 285 \mathrm{mOsm}$ ) consisting of (values in mM): 100 potassium acetate or potassium gluconate, $2 \mathrm{KCl}, 1 \mathrm{MgCl}_{2}, 5 \mathrm{EGTA}, 10$ HEPES, $20 \mathrm{KOH}$, and 43 biocytin. Biocytin was replaced by mannitol in the solution used to fill pipette shanks.

Electrodes were mounted in a Plexiglas holder with a pressure port. This port allowed the application of pressure pulses $(40-80 \mathrm{msec} ; 40 \mathrm{psi})$ from a Picospritzer (General Valve, Fairfield, NJ) or the manual application of suction or pressure from a $30 \mathrm{cc}$ syringe. The electrode was advanced in 1.5 $\mu \mathrm{m}$ steps (Burleigh 6000 microdrive) through the dorsal 5 layers of the torus. Responses were amplified using an electrometer (model 767; World Precision Instruments) and stored on videotape at $40 \mathrm{kHz}$ with 16 -bit resolution (model 3000; Vetter Instruments).

Recordings generally were made at several levels of negative holding current. This procedure permitted PSPs to be observed in the absence of spiking and other fluctuations associated with voltage-dependent conductances; generally less than $-0.2 \mathrm{nA}$ was used. As in previous studies (Fortune and Rose, 1997a,b; Rose and Fortune, 1999), these holding currents did not, with the exception of those neurons with all-or-nothing components of EPSPs, affect the temporal filtering properties of neurons. Resting potentials were between -55 and $-76 \mathrm{mV}$. At the conclusion of each intracellular recording, neurons were filled with biocytin by applying $1-2 \mathrm{nA}$ of positive DC for 1-3 min. Neurons were labeled to determine their location; only neurons in layers $2-5$ are reported in this study. Also, a qualitative analysis of neural morphology did not reveal any relation between morphological type and short-term synaptic plasticity.

Sensory stimuli. The search stimulus was designed to elicit responses from both ampullary and tuberous neurons in the torus. The ampullary component of the search stimulus was a linear frequency sweep (2-30 Hz; $5 \mathrm{sec}$ duration; $1-2 \mathrm{mV} / \mathrm{cm}$ at the fish's head) that was added to the S1 and presented through the electrodes in the mouth and at the tail. The tuberous component was the S1 and a sine wave (S2) $4 \mathrm{~Hz}$ higher than the S1 frequency that was delivered concurrently through one pair of the array of carbon electrodes surrounding the fish. Addition of the S2 and the S1 resulted in broad-field amplitude and phase modulations at a rate equal to the difference in frequencies of the S1 and S2; the modulation frequency is known as the "beat rate."

After a recording was established, the best stimulus (ampullary or tuberous) and stimulus orientation were determined. Stimulus orientation was chosen to elicit the strongest and most consistent responses from the neuron. The data presented here and in previous reports (Fortune and Rose, 1997a,b; Rose and Fortune, 1999) indicate that the temporal filtering properties of ampullary and tuberous neurons in the torus are highly similar.

Responses were first recorded while the stimulus frequency (ampullary) or beat rate (tuberous) was linearly scanned from $\sim 2$ to $30 \mathrm{~Hz}$. These "sensory scans" were 5 sec in duration. Subsequently "sensory bursts" were delivered, wherein stimulus frequency (ampullary) or beat rate (tuberous) was held at 5,10 , or $20 \mathrm{~Hz}$ for $1 \mathrm{sec}$ (Fig. $1 B, C$ ). One second transpired between the end of one burst and the start of the subsequent burst. For tuberous stimulation, the $\mathrm{S} 2$ was gated on at the zero-crossing of an S1 cycle, and its starting phase was adjusted differentially for E-type and I-type units. For neurons that were excited primarily by amplitude increases (E-units), the stimulus burst began with an amplitude decrease; the opposite relation held for I-units. This stimulation paradigm was used so that the first PSP elicited by the stimulus burst was in response to the same magnitude of amplitude modulation as subsequent PSPs. For ampullary stimulus bursts, only a single low-frequency signal was presented. The starting phase of the signal was adjusted such that the first quarter cycle of stimulation did not excite the neuron. Rarely were neurons encountered
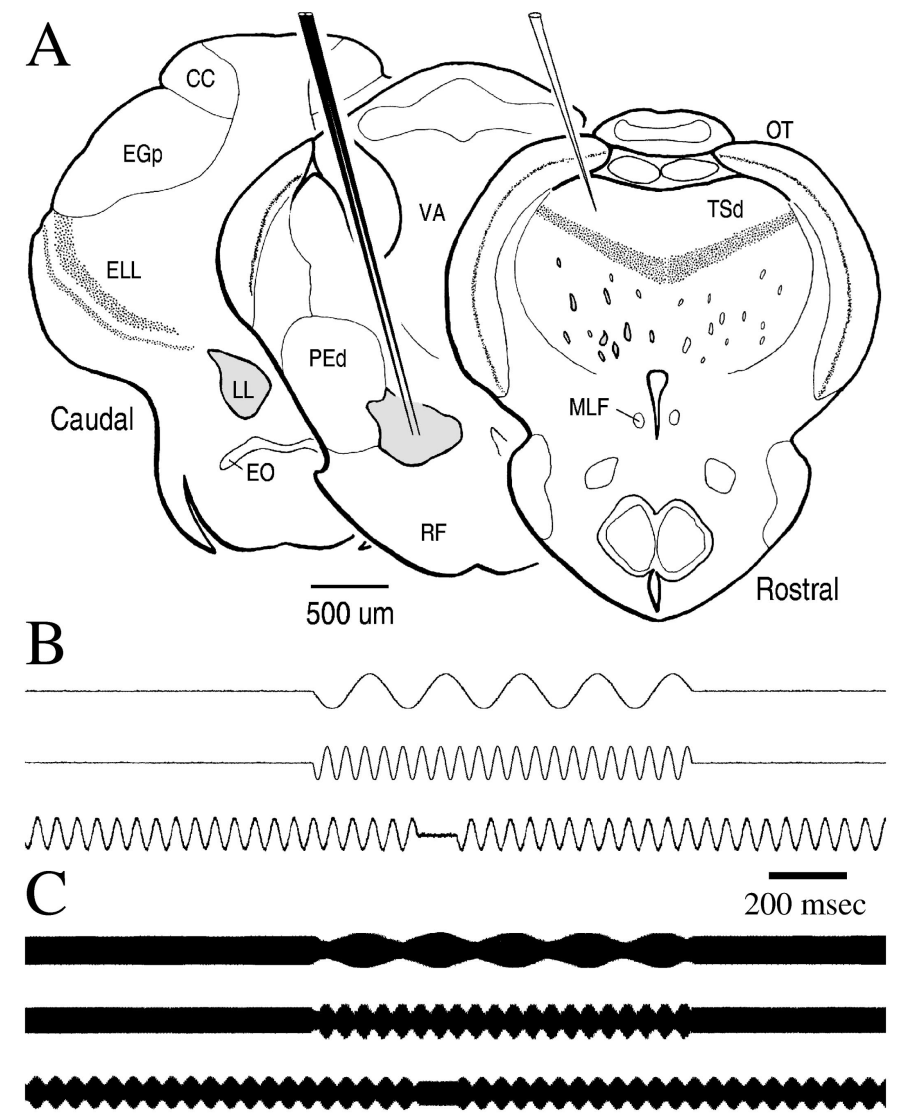

$\mathrm{D}$

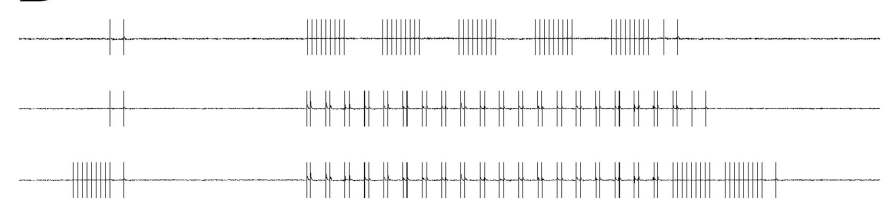

Figure 1. A, Locations of bipolar stimulating ( filled) and recording (open) electrodes. Typically the stimulating electrodes were placed $\sim 200-300 \mu \mathrm{m}$ caudal of the recording area. The recording pipette was advanced through layers $1-5$ of the dorsal torus semicircularis. Drawings were adapted from Carr and Maler (1986). CC, Corpus cerebellum; $E G p$, eminentia granularis posterior; $E L L$, electrosensory lateral line lobe; $E O$, efferent octavolateral nucleus; $L L$, lateral lemniscus; $M L F$, medial longitudinal fasciculus; $O T$, optic tectum; $P E d$, praeeminentialis dorsalis; $R F$, reticular formation; $T S d$, dorsal torus semicircularis; $V A$, valvula of cerebellum. $B$, Ampullary sensory stimuli. Top, Middle, Traces are 5 and $20 \mathrm{~Hz}$ "bursts," respectively, each $1 \mathrm{sec}$ in duration. Bottom, An ongoing $20 \mathrm{~Hz}$ sensory stimulus was interrupted by a gap (4-200 msec in this study). $C$, Tuberous sensory stimuli. These stimuli were generated by adding two sinusoidal signals of high frequency (see Materials and Methods). The amplitude envelope of these beating stimuli mirrored the temporal structure of the ampullary stimuli. D, Temporal patterns of LL stimulation. Top, Middle, A pair of pulses [35 msec interpulse interval (IPI)] preceded, by $510 \mathrm{msec}$, and a second pair followed a train of pulses (tetanus). The delay in the presentation of the post-tetanus pair of pulses ranged from 25 to $>600 \mathrm{msec}$. Within each tetanus, trains of pulses were delivered at rates of $5 \mathrm{~Hz}$ (top) or $20 \mathrm{~Hz}$ (middle). The $5 \mathrm{~Hz}$ tetanus consisted of five trains of pulses per second, each train having nine pulses presented at $100 \mathrm{~Hz}(10 \mathrm{msec}$ IPI). The $20 \mathrm{~Hz}$ tetanus consisted of 20 pairs of pulses $(10 \mathrm{msec}$ IPI; $40 \mathrm{msec}$ between pairs), which generally elicited PSPS that were similar to those in response to $20 \mathrm{~Hz}$ sensory stimulation. PSPs in response to the pairs of pulses before and after the tetanus were compared to determine whether synaptic depression or loss of facilitation was responsible for PSP depression during the tetanus. Bottom, To test whether PSP depression, induced by the $20 \mathrm{~Hz}$ tetanus, attenuated responses to longer duration trains, the first pulse of the pretetanus and post-tetanus pair was replaced with one to two trains that had 9-10 pulses, delivered at $100 \mathrm{~Hz}$. 

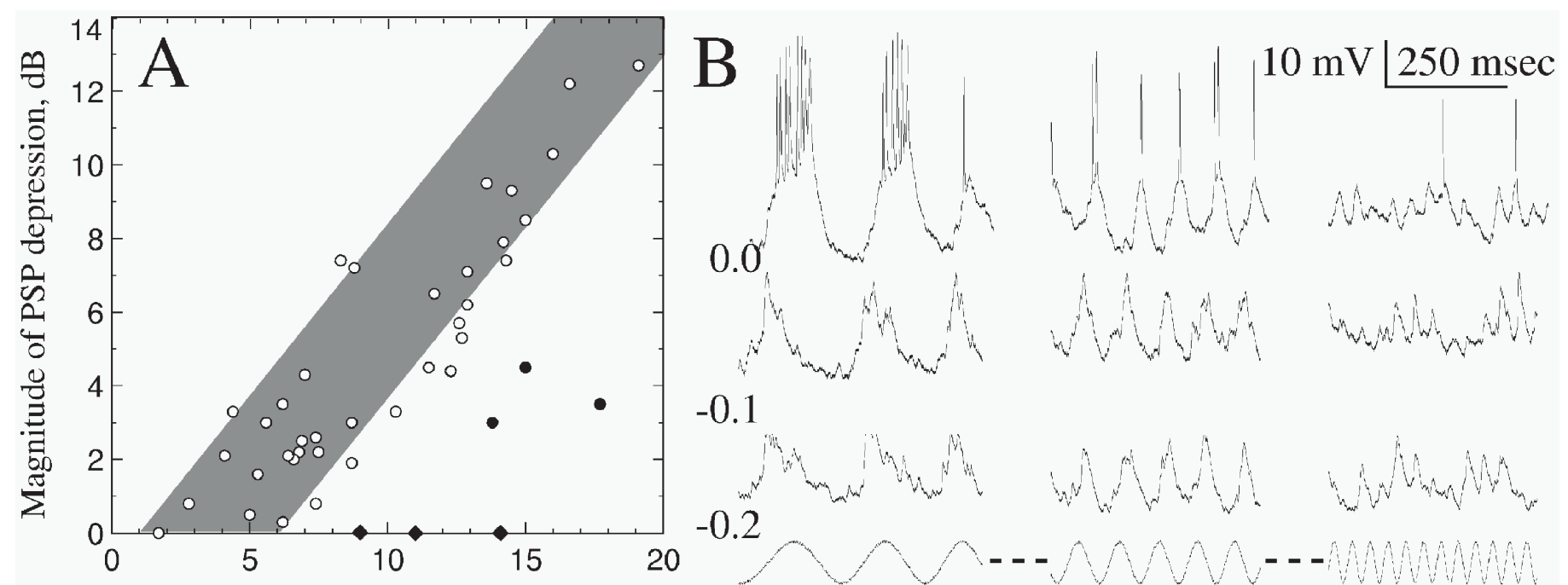

$-0.1$

20

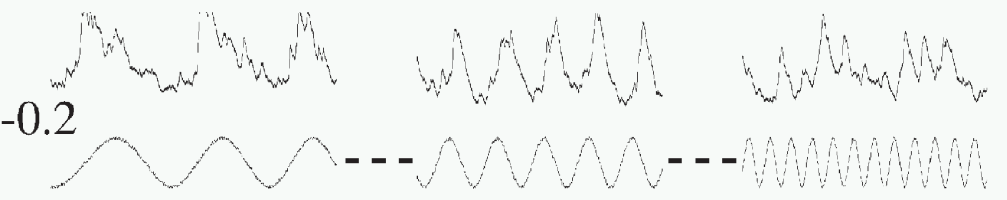

Magnitude of low-pass filtering, $\mathrm{dB}$
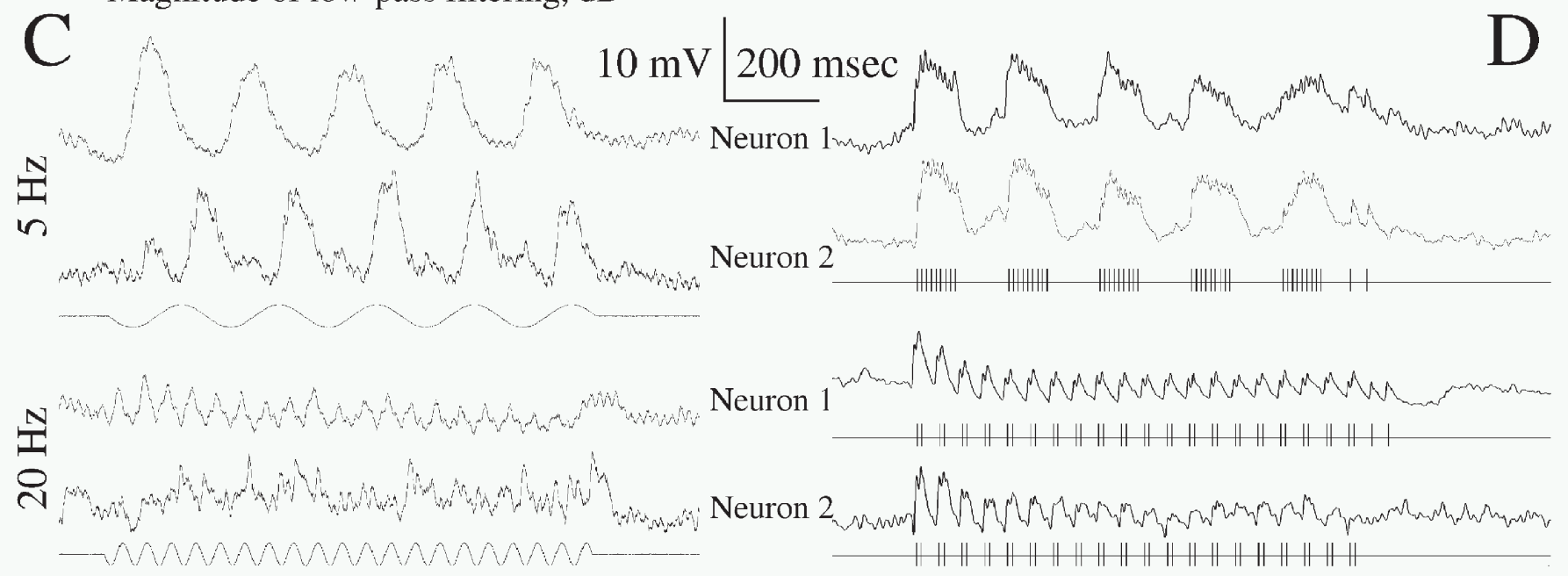

Figure 2. Site of PSP depression and its role in low-pass temporal filtering. A, Relation between the magnitude of low-pass filtering, measured from responses to linear sweeps of the frequency or the beat rate of the sensory stimulus $(B)$, and PSP depression, measured from responses to sensory bursts $(C)$. Previous work (Fortune and Rose, 1997a,b) demonstrated that low-pass filtering attributable to passive membrane properties of toral neurons ranges from 1 to $6 \mathrm{~dB}$. The gray area indicates the range within which passive membrane properties and short-term depression together might account for the low-pass filtering measured from sensory stimulus sweeps. Data to the right of this area indicate that an additional mechanism must contribute to the neuron's low-pass filtering; filled symbols highlight data points that fall well outside this range. Filled diamonds represent neurons that did not respond to $20 \mathrm{~Hz}$ or greater sensory bursts, and therefore no measurement for PSP depression could be made. Data were obtained from 43 neurons; 28 of these neurons also appear in Rose and Fortune (1999). B, Responses to linear sweeps, $5 \mathrm{sec}$ in duration, of stimulus frequency from 2 to $30 \mathrm{~Hz}$ (sensory scans, ampullary). This figure shows three segments (left to right) of a sweep (stimulus at bottom) and the corresponding intracellular recordings. Traces show responses of one neuron to presentations of the sensory stimulus while recording at different levels of holding current (in nanoamperes). Enhancement of PSP amplitude at the lowest frequencies in the sensory stimulus occurred primarily in recordings at the normal resting potential ( $-65 \mathrm{mV}$; compare responses at holding currents of $0.0,-0.1$, and $-0.2 \mathrm{nA}$ ), indicating a role of active membrane properties in temporal filtering. The low-pass filtering data shown in $A$ were obtained from responses at holding currents that minimized the contribution of active membrane properties. $C$, Responses of two neurons to 5 and $20 \mathrm{~Hz}$ sensory stimuli. $D$, Responses of the same two cells to stimulation of the LL at rates of 5 and $20 \mathrm{~Hz}$ (see Fig. $1 D$ ). Resting potentials of neurons 1 and 2 were approximately -76 and $-55 \mathrm{mV}$, respectively.

that had both strong E and I components of their responses. These neurons were excluded from the analyses presented in this paper. Finally, ongoing sensory stimuli of $20 \mathrm{~Hz}$ frequency (ampullary) or beat rate (tuberous) were presented with $48 \mathrm{msec}$ or longer "gaps" that occurred at intervals of $1 \mathrm{sec}$ (Rose and Fortune, 1999). For ampullary neurons, gaps had no electrosensory stimulus; in tuberous neurons, only the S1 was present (see Fig. $1 B, C)$.

Stimulation of the lateral lemniscus. Stimulus pulses $(0.2 \mathrm{msec})$ were generated by a Grass stimulator (model S44; Quincy, MA) and delivered through an isolation unit (SIU-5; Grass). Pulse amplitude (range, 2-8 V) was adjusted for each recording to elicit consistent responses. During stimulation of the LL, an S1 was generally present. In several recordings from ampullary cells, LL stimulation was done both in the presence and absence of an S1, without apparent differences in responses.

The rate and pattern of LL stimulus pulses were designed to elicit PSPs that mimicked the responses of cells to electrosensory stimuli. Preliminary experiments showed that a pulse repetition rate of $100 \mathrm{~Hz}$, approximating the peak firing rate of ELL cells (J. Bastian, personal communication) generated PSPs in toral neurons that most closely resembled those elicited by sensory stimuli. The rate of presentation of trains of pulses was varied
$(5,10$, and $20 \mathrm{~Hz})$. For each rate, the train duration was adjusted to elicit PSPs that, on average, most closely resembled those that were observed for sensory stimulation of that temporal frequency. For example, $5 \mathrm{~Hz} \mathrm{LL}$ bursts typically were composed of five 200 msec segments; each segment consisted of a $90 \mathrm{msec}$ train of LL pulses, delivered at a rate of $100 \mathrm{~Hz}$ (a train is composed of nine LL pulses with $10 \mathrm{msec}$ interpulse intervals), followed by $110 \mathrm{msec}$ with no stimulus (Fig. $1 D$ ).

Correspondence between sensory and LL stimulation paradigms was assessed by recording responses while holding this "train rate" constant for periods of $1 \mathrm{sec}$. A train rate of $20 \mathrm{~Hz}$ was commonly used to generate PSP depression. This stimulus consisted of 20 pairs of pulses $(10 \mathrm{msec}$ interval between pulses of a pair; $40 \mathrm{msec}$ between the last pulse in one pair and the first pulse in the next pair) and is referred to as the "tetanus (20 Hz)."

Pairs of LL pulses were presented to assess the presence and strength of synaptic depression or facilitation. In preliminary experiments the interpulse interval and the rate of presentation of paired pulses were systematically varied; interpulse intervals of 35 and $55 \mathrm{msec}$ were used in this study. Intervals of $250 \mathrm{msec}$ between paired pulses were sufficient for full recovery of the PSP amplitude to that elicited by the first LL pulse of the pair. 

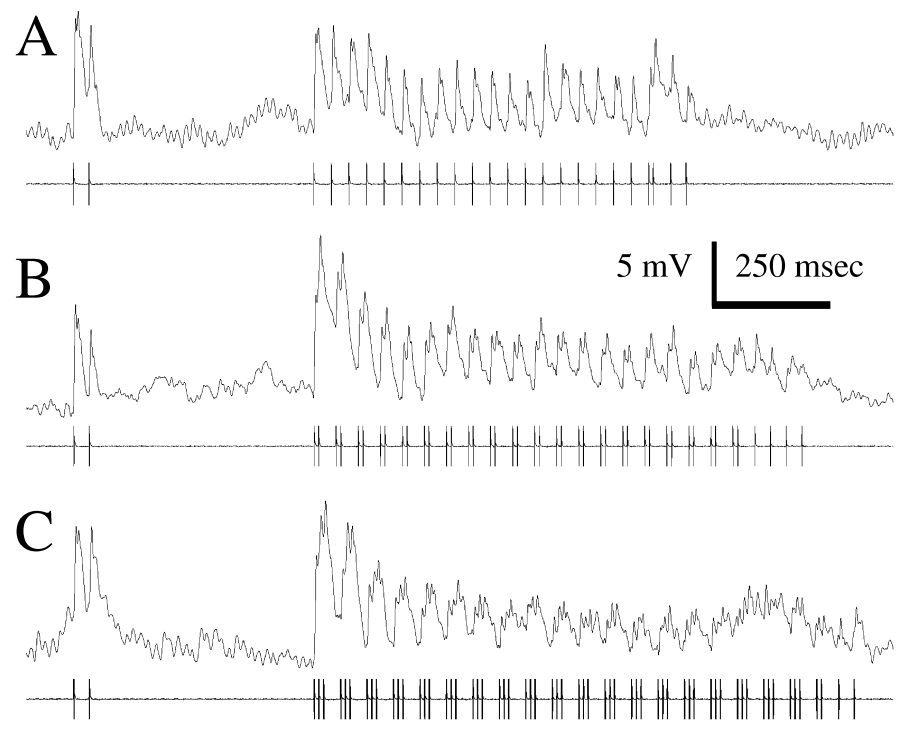

Figure 3. Duty cycle of lateral lemniscal stimulation affects the magnitude of PSP depression. A pair of pulses ( $35 \mathrm{msec}$ IPI) was followed by a tetanus that was a train of either single pulses $(A)$, pairs of pulses $(B)$, or triplets $(C)$. During the tetanus, the interpulse interval within pairs or triplets of pulses was $10 \mathrm{msec}$; the gap between pulse groups was $35 \mathrm{msec}$. Thirty-five milliseconds after the tetanus a pair of pulses was delivered (10 msec IPI), followed by two to four single pulses ( $35 \mathrm{msec}$ IPI). The resting potential was $-76 \mathrm{mV}$; recordings were made at a holding current of $-0.1 \mathrm{nA}$.

Recovery from synaptic depression or loss of facilitation was assessed by examining the ratio PSP1/PSP2 for paired pulses before and after tetanus $(20 \mathrm{~Hz})$. The initial paired pulse was presented $510 \mathrm{msec}$ before the tetanus. Post-tetanus paired pulses were delivered after 25-600 msec intervals (Fig. 1D).

The ability of neurons to respond to low temporal-frequency stimuli in the presence of high frequency stimuli was assessed by presenting a stimulus train $(100 \mathrm{msec} ; 100 \mathrm{~Hz})$ before and after the $20 \mathrm{~Hz}$ tetanus. This LL stimulus train is identical to those used in $5 \mathrm{~Hz}$ bursts. Trains of this frequency and duration have been shown to be effective in eliciting facilitation at other synapses in the electrosensory system (Berman et al., 1997).

Analysis of neurophysiological data. For analysis, responses to several presentations of each stimulus were averaged. As in previous studies (Fortune and Rose, 1997b; Rose and Fortune, 1999), the temporal filtering profiles of neurons were determined by Fourier analysis of segments of the averaged intracellular responses to sensory scans. In repeated measures of PSP amplitude using this methodology, we found that the values varied by less than $\pm 0.5 \mathrm{~dB}$.

PSP depression was measured by comparing the PSP amplitude for the initial 100 msec segment of sensory or LL bursts with that for a segment of identical duration at the end of the burst. In some cases PSP depression was fully activated in $<50 \mathrm{msec}$. In those cases the peak-to-peak amplitude (in millivolts) of PSPs was measured at the beginning (Vi) and end (Ve) of the burst. The ratio of these values was taken and expressed in decibels: $\mathrm{dB}=$ $20 \log (\mathrm{Vi} / \mathrm{Ve})$.

When PSPs to each pulse of a pair were discrete, depression or facilitation was measured by a simple amplitude ratio: PSP1/PSP2. Ratios $>1$ indicate synaptic depression and $<1$ indicate facilitation.

\section{RESULTS}

\section{Site of PSP depression and contribution to temporal filtering}

We tested the hypothesis that short-term PSP depression (Rose and Fortune, 1999) is caused primarily by processes in the torus. PSP depression is a decline over time in the amplitude of PSPs that are elicited by a sensory stimulus of a particular temporal frequency (Fig. $2 C, 20 \mathrm{~Hz}$, Neuron 1). This short-term plasticity contributes prominently to the temporal filtering properties of most toral neurons (Fig. 2A). Exceptions to this generalization (Fig. 2A, filled symbols) responded well to stimuli of low temporal frequency (Fig. $2 C, 5 \mathrm{~Hz}$, Neuron 2) but poorly for temporal frequencies of $20 \mathrm{~Hz}$ or more (Fig. 2C, $20 \mathrm{~Hz}$, Neuron 2).

For neurons that showed PSP depression to sensory stimuli of 20 $\mathrm{Hz}$, direct stimulation of their afferents (in the lateral lemniscus) with pairs of pulses, presented at a rate of $20 \mathrm{~Hz}$, also resulted in

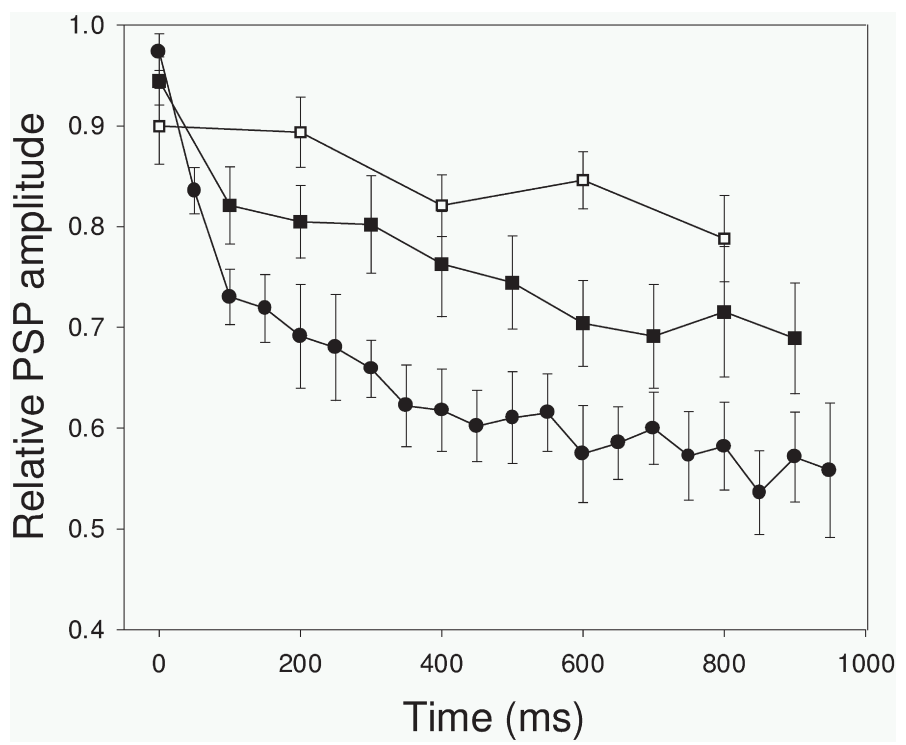

Figure 4. Time course and frequency dependence of PSP depression. PSPs were elicited by stimulating the lateral lemniscus with temporal sequences, of $1 \mathrm{sec}$ duration and $2 \mathrm{sec}$ intersequence interval, of pulses. Within each sequence, pulse trains $(100 \mathrm{~Hz})$ consisted of nine, five, or two pulses, repeated at rates of 5,10 , or $20 \mathrm{~Hz}$, respectively. For each neuron, PSP amplitudes were normalized with respect to the largest (mean) PSP recorded for each stimulus condition. Open squares are data from $5 \mathrm{~Hz}$ stimulation data, filled squares are from $10 \mathrm{~Hz}$ data, and filled circles are from $20 \mathrm{~Hz}$ data. The time ( $x$-axis) of occurrence of the first PSP in response to the stimulus was designated the 0 point. Means and SEs are plotted $(n=11)$.

PSPs that depressed over time (Fig. 2, compare $C, D, 20 \mathrm{~Hz}$ traces). Stimulation with trains of pulses, presented at a rate of 5 trains/sec, like $5 \mathrm{~Hz}$ sensory stimulation, elicited comparatively little PSP depression. These data indicate that toral processes can contribute to PSP depression.

In cells that responded poorly to sensory stimulation at $20 \mathrm{~Hz}$, stimulation of the lateral lemniscus at a periodicity of $20 \mathrm{~Hz}$ elicited PSPs (Fig. 2D, Neuron 2). These data support the hypothesis that processes upstream (at the ELL) can contribute to the low-pass temporal filtering properties of some toral cells and exclude the possibility that a failure of synaptic transmission in the torus underlies the weak responses of these cells to sensory stimuli of 20 $\mathrm{Hz}$ or more. In some of these neurons, PSP depression can be seen in responses to $20 \mathrm{~Hz}$ LL stimulation (Fig. 2D, Neuron 2). The time course and magnitude of this depression were similar to those seen in neurons that showed PSP depression to $20 \mathrm{~Hz}$ sensory stimulation; these data support the idea that PSP depression occurs downstream of the ELL.

The correspondence between PSP depression elicited during sensory versus lateral lemniscal stimulation depended on the temporal structure of the pulse train (Fig. 3). Depression of PSP amplitude increased with the stimulus duty cycle (the proportion of time the stimulus train was on vs off). The duty cycle was varied by presenting 1-3 pulses/group, while holding the gap between groups at $35 \mathrm{msec}$. Small differences between PSP depression in response to sensory versus lateral lemniscal stimulation may, therefore, be attributable to differences in the temporal characteristics of synaptic transmission for these two conditions.

Figure 3 also shows the responses of this neuron to a pair of pulses (35 msec IPI) presented before the stimulus trains and to pairs of pulses (10 and $35 \mathrm{msec}$ IPIs) presented after the trains. The amplitudes of PSPs to pairs of stimulus pulses after the train, relative to those elicited by the pair of pulses that preceded the train, were inversely related to the duty cycle of the stimulus train. Also, in all three conditions, PSPs to the first pair of pulses were larger than those after the stimulus train. These findings support the hypothesis that the decline in PSP amplitude during these trains was caused by synaptic depression. 


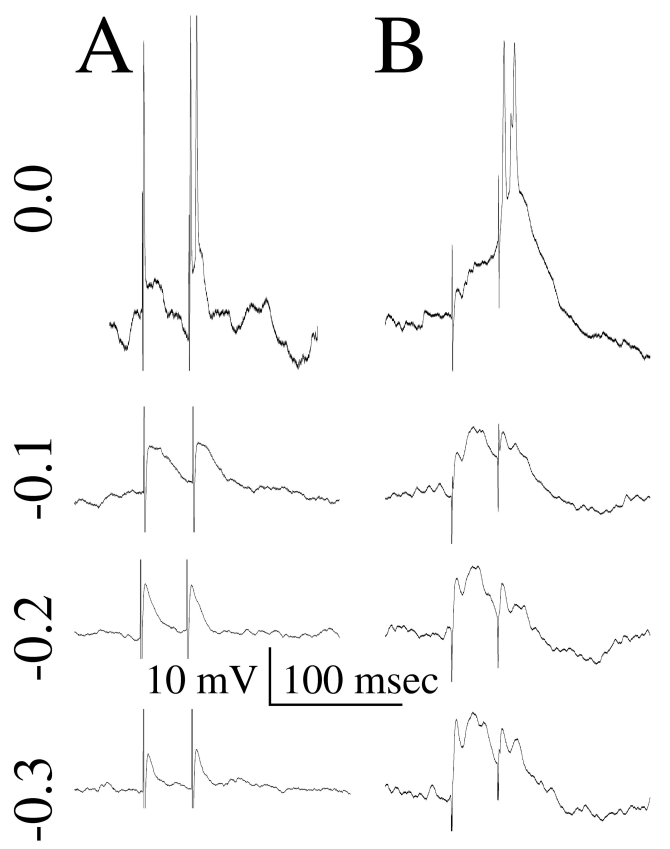

Figure 5. Responses to paired-pulse stimulation. $A$, Neuron with predominantly fast-type PSPs to LL stimulation. The resting potential was -60 $\mathrm{mV}$. $B$, Neuron with strong slow-type PSPs to LL stimulation. The resting potential was $-65 \mathrm{mV}$. Holding currents are shown in nanoamperes. Traces shown for the 0.0 holding current condition are from single-stimulus presentations; averaged traces $(n>5)$ are for -0.1 to $-0.3 \mathrm{nA}$.

The time course of PSP depression for stimulation of the lateral lemniscus at a rate of 5,10 , or $20 \mathrm{~Hz}$ was measured for 11 neurons (Fig. 4). The magnitude of depression was frequency dependent and closely resembled that for sensory stimulation at these frequencies (Rose and Fortune, 1999). At a stimulation periodicity of 20 $\mathrm{Hz}$ (Fig. 4, filled circles), the decline in PSP amplitude was well fit $\left(R^{2}=0.98\right)$ by a double-exponential function having first-order and second-order time constants of 82.9 and $4.35 \mathrm{sec}$, respectively.

\section{Time course of PSPs}

Stimulation of the lateral lemniscus with pairs of pulses elicited EPSPs in 40 cells. For presentation purposes, "fast" and "slow" components of these PSPs are identified. When the fast component was seen in relative isolation (e.g., Fig. $5 A$ ), the median latency (to peak) was $4.4 \mathrm{msec}(n=22$; range, $2.0-10.2)$, and the median decay time (peak to baseline) was $18.6 \mathrm{msec}$ (range, 9.9-38.5). In nine cases, the slow-type PSP was predominant (Fig. 5B) and could be measured independently. The slow component had a median latency (to peak) of $15.9 \mathrm{msec}(n=9$; range, 9.7-24.7) and a decay time of $43.6 \mathrm{msec}$ (range, 29-130). The slight overlap in time course measurements for these two groups probably reflects a small contribution of the slow component to some of the PSPs that appeared to be exclusively of the fast type. Median values, therefore, best reflect the differences in the time course of the fast and slow components.

The differential time courses of these fast and slow PSP types were relatively invariant over a wide range of holding currents (Fig. 5). The differences in PSP type across neurons were, therefore, not simply an artifact of recording at different levels of polarization; current clamp of $-0.1 \mathrm{nA}$ corresponds to $\sim 10-15 \mathrm{mV}$ of hyperpolarization. As will be shown below, these two PSP types are associated with different roles in the filtering of temporal patterns of inputs. The remaining nine neurons had slow and fast PSPs that could not be measured separately.

\section{Mechanism of PSP depression: synaptic depression or loss of facilitation?}

Theoretically, PSP depression could result from a decline in the efficacy of synaptic transmission (synaptic depression) or a loss of

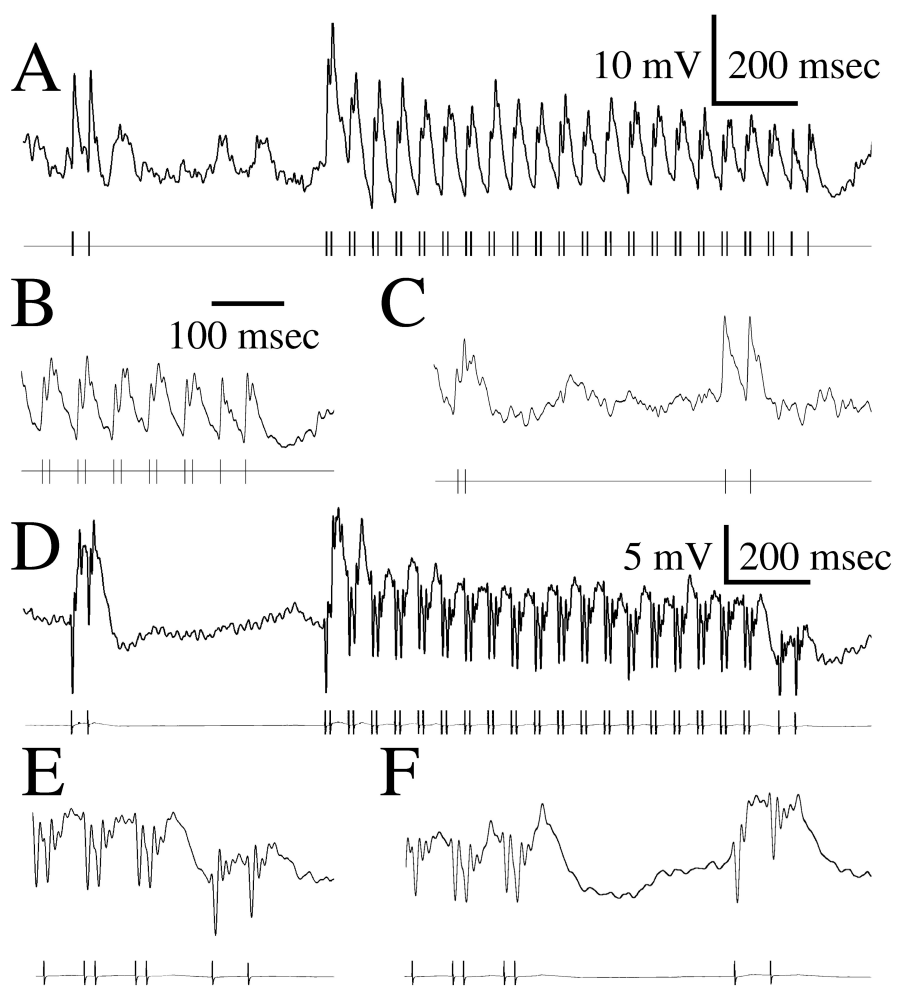

Figure 6. PSP depression and recovery after a train of pulse pairs (10 $\mathrm{msec}$ interpulse interval), referred to as tetanus $(20 \mathrm{~Hz}) . A-C$, Neuron with fast-type PSPs (resting potential, $-65 \mathrm{mV}) . A$, Pairs of pulses $\left(\mathrm{P}_{1}, \mathrm{P}_{2}\right)$ followed by a tetanus $(20 \mathrm{~Hz})$. An identical paired pulse follows the tetanus (35 msec delay). $B$, Time-expanded view of responses to the end of the tetanus and the second paired pulse shown in $A$. $C$, Post-tetanus delay of 350 msec. $D-F$, Same as $A-C$ but for a neuron with slow-type PSPs. The time scale for $E$ and $F$ is the same as that for $B$ and $C$.

facilitation. To distinguish between these possibilities, the pairedpulse stimulation paradigm, shown in Figures $1 D$ and 6 , was used. First, the LL was stimulated with a pair of pulses ( $35 \mathrm{msec}$ IPI). After a recovery period of $510 \mathrm{msec}$, a tetanus ( $20 \mathrm{~Hz}$ periodicity) was delivered for $1 \mathrm{sec}$. This tetanus consisted of a sequence of 20 pairs of pulses (10 msec IPI for each pair), presented at a rate of 20 pairs/sec. Subsequently, another pair of pulses (35 msec IPI) was delivered. Synaptic depression should attenuate the amplitude of the PSP that is elicited by the second pulse in a pair. The synaptic

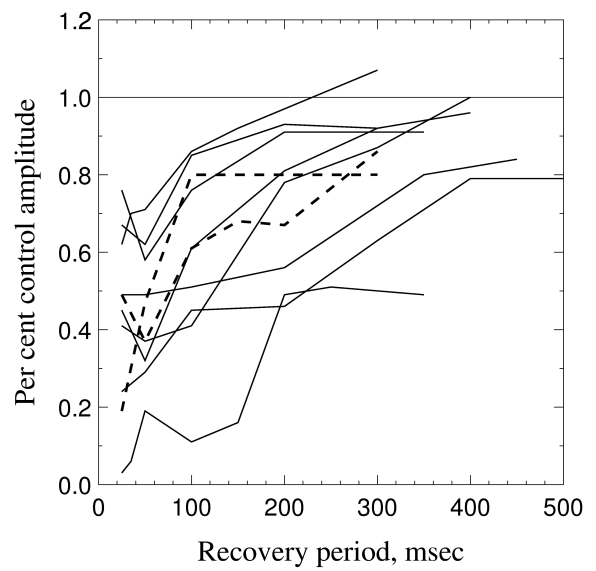

Figure 7. Time course for recovery from PSP depression. The plot shows the percent recovery of PSP amplitude (relative to PSPs to the first pulse in the pretetanus pair) versus the delay of stimulation after the depressing tetanus $(20 \mathrm{~Hz})$. Solid lines represent neurons with predominantly fast-type PSPs; dashed lines represent those with strong slow-type PSPs. 
depression hypothesis would be supported, therefore, if PSP1/PSP2 is $>1.0$ before the tetanus and is $\sim 1.0$ after the tetanus; PSP1 (pretetanus) should also be greater than PSP1 (post-tetanus). Alternatively, the loss-of-facilitation hypothesis would be supported if PSP1/PSP2 is $<1.0$ before the tetanus and approximately equal to 1.0 after the tetanus.

Representative recordings from fast- and slow-PSP neurons in response to this $\mathrm{P}_{1} \mathrm{P}_{2}$-tetanus $(20 \mathrm{~Hz})-\mathrm{P}_{1} \mathrm{P}_{2}$ stimulus regimen are shown in Figure 6, $A-C$ and $D-F$, respectively. In both cases, PSP depression occurred during the tetanus (Fig. 6 $A, D$ ). Discrete PSPs in response to each pulse in the initial pair of pulses were seen for the fast-PSP cell but not for the slow-PSP type. Nevertheless, for both fast- and slow-PSP neurons, PSPs elicited by the pair of pulses after the tetanus were substantially smaller than those in response to the pair of pulses that preceded the tetanus. Also, the ratios of the amplitudes of PSP1 to PSP2 were similar for both pretetanus and post-tetanus pairs of pulses. These data suggest that synaptic depression underlies the decline in PSP amplitude during the tetanus. Furthermore, as the interval between the end of the tetanus and the post-tetanus pairs of pulses was increased, the amplitude of resulting PSPs also increased, suggesting recovery from short-term synaptic depression. For most neurons $75 \%$ of the control amplitude was achieved within $400 \mathrm{msec}$ of the tetanus (Fig. 7).

Population data for PSP1/PSP2 ratios are shown in Figure 8. Thirty-six cells were judged suitable for making these ratio calculations; neurons were excluded if the amplitudes of individual PSPs could not be unambiguously measured, which included most slowPSP cases (see Fig. 6D-F).

Twenty-seven of these neurons showed PSP1/PSP2 $>1.0$, and greater ratios were associated with greater PSP depression during the tetanus (Fig. 8). The post-tetanus PSP ratios in 19 of these cases were slightly $<1$, probably reflecting some recovery from depression during the $35 \mathrm{msec}$ that separated the pulses. The remaining nine neurons showed weak facilitation, and the PSP ratio posttetanus was similar to that pretetanus. Finally, in two cases, PSPs after tetanus were too small to be measured accurately. Taken as a whole, these data strongly support the hypothesis that PSP depression during the tetanus was caused by synaptic depression.

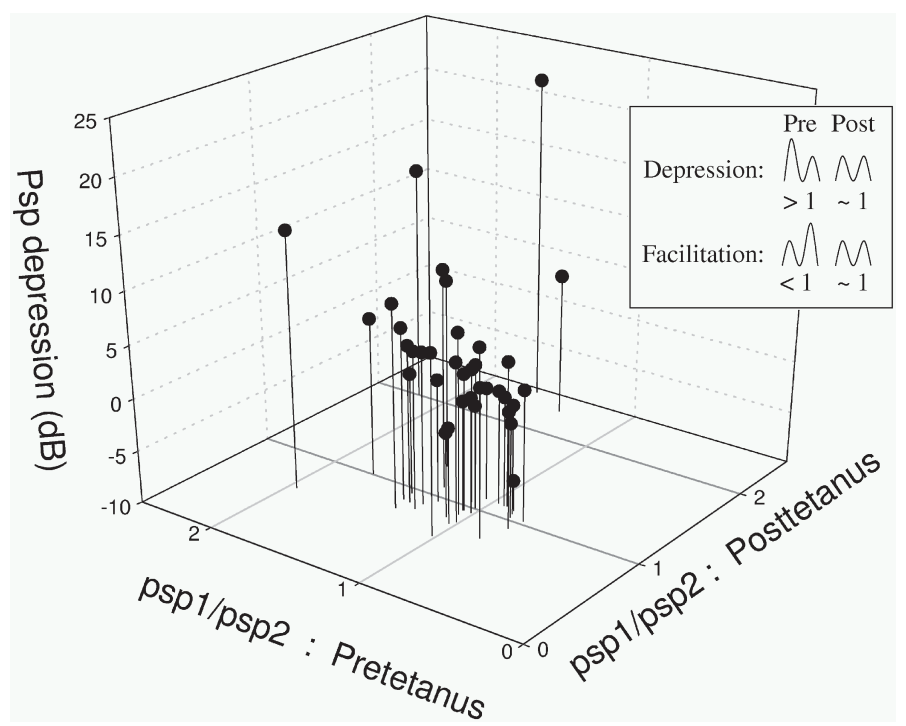

Figure 8. Roles of synaptic depression and loss of facilitation in PSP depression. A pair of pulses was presented $510 \mathrm{msec}$ before the tetanus $(20$ $\mathrm{Hz}$ ) (see Fig. 6), and a second pair was presented $35 \mathrm{msec}$ after the tetanus $(20 \mathrm{~Hz})$. The PSP1/PSP2 ratio is the amplitude (in millivolts) of the PSP resulting from the first LL pulse divided by the amplitude of the PSP from the second LL pulse, delivered $35 \mathrm{msec}$ after the first. PSP depression is the decline in PSP amplitude during the $1 \mathrm{sec}$ duration tetanus $(20 \mathrm{~Hz})$. Inset, The results expected if PSP depression (top) or loss of facilitation (bottom) primarily accounts for PSP depression. Three trends are visible in the data: pretetanus PSP ratios are $>1$, post-tetanus values are near 1 , and greater PSP depression is associated with greater paired-pulse depression.

\section{Does synaptic depression preclude transmission of biologically relevant information?}

The finding that synaptic depression underlies PSP depression presents an apparent paradox; if low-pass filtering, i.e., rejection of fast temporal-frequency information, is achieved at the expense of depressing synaptic transmission in general, then the functionality of the filter is defeated. It was of interest, therefore, to determine
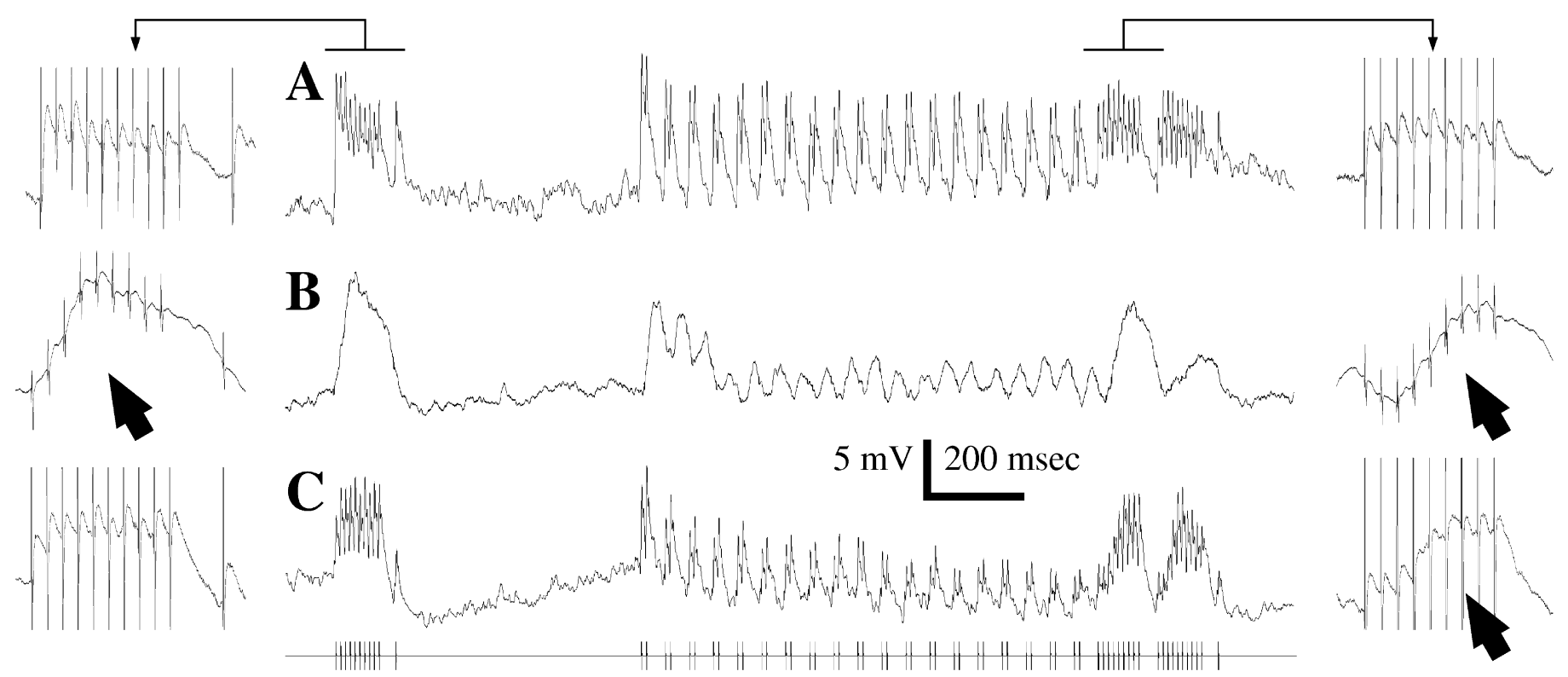

Figure 9. Responses to pulse trains $(9-10$ pulses at $100 \mathrm{~Hz})$ before and after the induction of synaptic depression by a tetanus $(20 \mathrm{~Hz})$. The stimulus is depicted at the bottom. The $100 \mathrm{~Hz}$ train was presented once before tetanus and twice after tetanus, and a single pulse occurred $35 \mathrm{msec}$ after the pretetanus train and the second post-tetanus train. $A-C$, Low-pass filtered $(153 \mathrm{~Hz}$ corner $)$ and averaged $(n>3)$ responses of three neurons. On both the left and right, time-expanded traces show unfiltered responses to the trains. $A$ and $B$ were the most common responses; $C$ was rarely encountered. $A$, A fast-PSP neuron. $B$, A slow-PSP neuron. $C$, A fast-PSP neuron in which synaptic depression does not reduce responses to $100 \mathrm{~Hz}$ trains. Arrows indicate facilitation. 


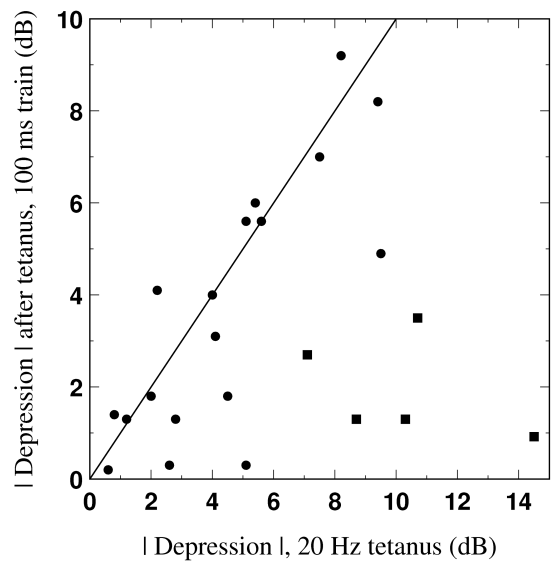

Figure 10. Attenuation of PSPs to pulse trains $(9-10$ pulses at $100 \mathrm{~Hz})$ versus the magnitude of synaptic depression induced by the tetanus $(20 \mathrm{~Hz})$ Trains were presented before and after a $1 \mathrm{sec}$ duration tetanus $(20 \mathrm{~Hz})$ (stimulus paradigm shown in Fig. 9). The $y$-axis is the decline in amplitude of PSPs to the post-tetanus train relative to that to the pretetanus train. Data are from neurons with predominantly fast-type PSPs (circles) or slow-type PSPs (squares). The line indicates 1:1 correspondence between depression during the tetanus and to the $100 \mathrm{~Hz}$ train (post vs pre).

whether PSP depression, induced by the tetanus $(20 \mathrm{~Hz})$, would attenuate responses to a train of pulses that represented a temporal pattern of information that would be present in response to a sensory stimulus of low temporal frequency (e.g., $5 \mathrm{~Hz}$ beat rate).

This analysis was performed by modifying the $\mathrm{P}_{1} \mathrm{P}_{2}$-tetanus $(20$ $\mathrm{Hz}$ ) $-\mathrm{P}_{1} \mathrm{P}_{2}$ paradigm (see Fig. $1 D$ ). Pretetanus, $\mathrm{P}_{1}$ was replaced by a train of 8-10 pulses, each separated from its neighbor by $10 \mathrm{msec}$. Post-tetanus, $P_{1}$ was replaced by 1 or 2 of these pulse trains (Fig. 9); pulse trains of this type will be identified with respect to the number of pulses and the pulse rate (e.g., 9 pulses at $100 \mathrm{~Hz}$ ). The hypothesis that synaptic depression induced by the $20 \mathrm{~Hz}$ tetanus attenuates, in a generalized manner, synaptic transmission for other temporal patterns of afferent activity would be supported if the amplitudes of PSPs elicited by the post-tetanus $100 \mathrm{~Hz}$ trains were attenuated (relative to the pretetanus train) proportionate to the magnitude of PSP depression induced by the $20 \mathrm{~Hz}$ tetanus.

This hypothesis was supported for approximately half of the cells, and an example is shown in Figure $9 A$. This recording was representative of most neurons that had fast-type PSPs (Fig. 10, circles). The time-expanded sections (Fig. 9) show that PSP amplitude quickly reached its maximal value during these trains $(9-10$ pulses at $100 \mathrm{~Hz}$ ) and that individual PSPs were clearly discernable. For neurons that had predominantly slow PSPs (Fig. 9B), however, temporal summation and facilitation occurred. Facilitation was particularly prominent to the $100 \mathrm{~Hz}$ pulse train that immediately followed the tetanus $(20 \mathrm{~Hz})$. Most importantly, PSPs in response to the $100 \mathrm{~Hz}$ train after the tetanus $(20 \mathrm{~Hz})$ were nearly as large as those to the train before the tetanus (Fig. 10, squares). The second $100 \mathrm{~Hz}$ train of pulses after the tetanus $(20 \mathrm{~Hz})$, however, elicited smaller PSPs, suggesting that additional depression had taken place. Facilitation and temporal summation were most com- mon among the slow-PSP neurons; however, occasionally this was seen in cells that appeared to have predominantly fast-type PSPs (Fig. $9 C$ ). As in the case of the slow-PSP types, these processes contributed to the equalization of the amplitude of PSPs to the 100 $\mathrm{Hz}$ trains before and after the tetanus $(20 \mathrm{~Hz})$.

\section{Roles of active membrane properties and network features in passing low temporal-frequency information}

Fortune and Rose (1997b) showed that voltage-dependent conductances serve to amplify the underlying temporal selectivities of toral neurons for sensory stimulation (see Figs. $2 B, 11 A$ ). In the present study, limited data suggest that slow-type PSPs may be particularly effective in triggering these all-or-none depolarizations. In the representative case shown in Figure $11 B$, the all-ornone depolarization was triggered by the late, slow PSP when the cell was current-clamped at $-0.1 \mathrm{nA}$, but not when the current clamp was increased to $-0.3 \mathrm{nA}$ (Fig. $11 C$, traces at these two values of current clamp overlaid). When the current clamp was removed, these depolarizations resulted in spikes (Fig. 11D). Near the resting potential, active membrane properties, therefore, can further enhance the responses of neurons to low temporalfrequency information, despite synaptic depression. The relative effectiveness of fast- versus slow-type PSPs in triggering all-or-none components of PSPs should be examined in more detail in future studies.

As shown in Figure 10, for approximately half of the cells recorded, PSP depression [induced by the tetanus $(20 \mathrm{~Hz})$ ] proportionately attenuated the amplitude of PSPs elicited by LL pulse trains that represented low temporal-frequency information (Fig. $12 \mathrm{~A}$ ). Even in these cases, however, strong responses could be observed to low temporal-frequency sensory information that was embedded in an otherwise continuous sensory stimulus that had a beat rate or frequency of $20 \mathrm{~Hz}$ (Fig. 12B,C). In this case, the PSPs that were elicited by a sequence of five pulses were similar in duration to those that occurred in response to a $28 \mathrm{msec}$ gap in an otherwise continuous sensory stimulus of $20 \mathrm{~Hz}$. The large PSPs that were elicited by the gap in the sensory stimulus resulted, in part, from active membrane properties (Fig. 12, compare traces at -0.2 vs $-0.1 \mathrm{nA}$ current clamp). The discrepancy seen in this neuron (at $-0.2 \mathrm{nA}$ current clamp) between PSP amplitude in response to sensory versus lateral lemniscal stimulation, however, suggests that some afferent input to this particular neuron was low-pass and, therefore, experienced little synaptic depression during $20 \mathrm{~Hz}$ sensory stimulation.

\section{DISCUSSION}

Frequency-dependent depression of PSP amplitude contributes to low-pass temporal filtering in the torus (Rose and Fortune, 1999). Our objectives were to (1) determine whether this depression is attributable to processes in the torus or upstream and (2) investigate the mechanism(s) underlying PSP depression. We found that PSP depression is generated in the torus and is caused by synaptic depression. This depression was frequency dependent and was similar in time course to PSP depression for sensory stimulation. In addition, stimulation of the lateral lemniscus revealed fast and slow PSP types. Paradoxically, many neurons responded strongly to a

Figure 11. All-or-none components of PSPs, resulting from active membrane properties, were triggered by slow-type PSPs. $A$, Responses to a 48 msec gap in an ongoing $20 \mathrm{~Hz}$ stimulus (ampullary). At $-0.1 \mathrm{nA}$ holding current, a large PSP is present during this gap. At $-0.3 \mathrm{nA}$ holding current, this response is markedly smaller. $B$, PSPs elicited at these holding currents by pairs of pulses (50 msec interpulse interval). $C$, Responses to pairs of pulses -0.1 and $-0.3 \mathrm{nA}$ overlaid. The large, all-or-none component is not triggered by voltage alone; rather it arises out of the slow peak of the PSP in response to the second pulse. $D$, Responses to a pair of pulses at no holding current. The resting potential was $-65 \mathrm{mV}$.

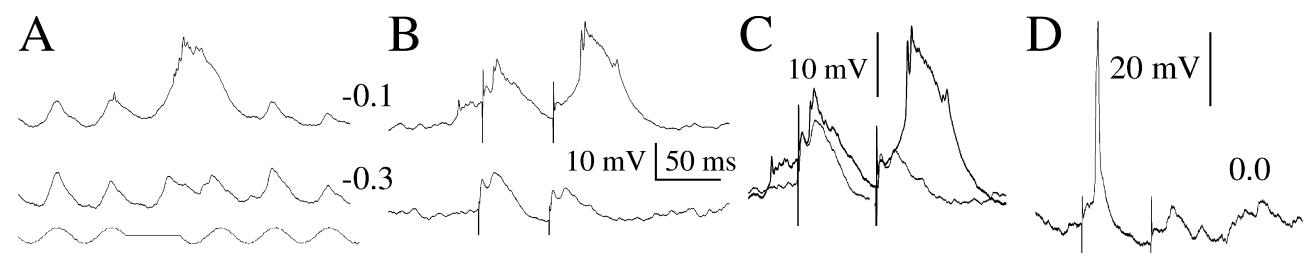




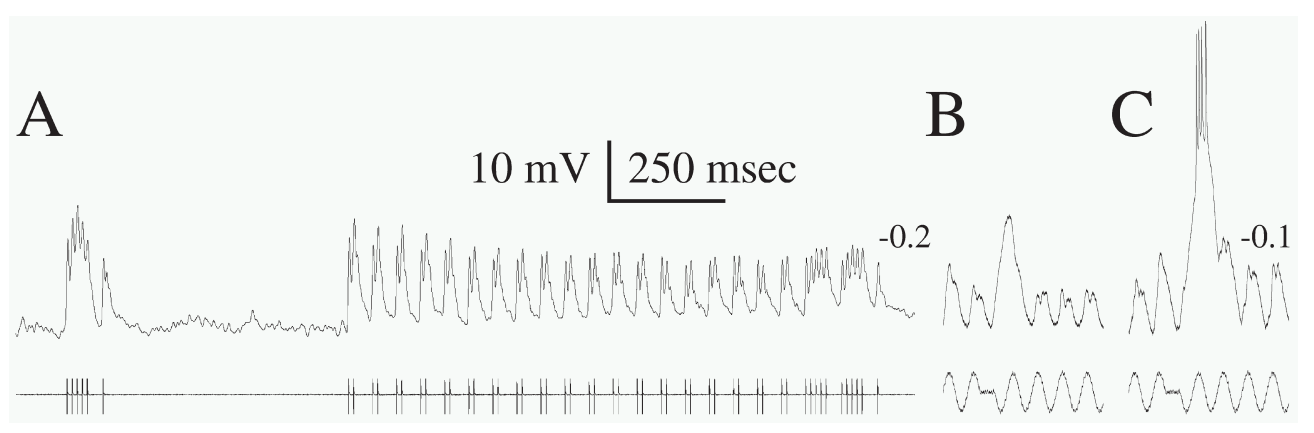

Figure 12. Network properties can circumvent synaptic depression. A, A 50 msec train $(100 \mathrm{~Hz})$ was presented once before and twice after the tetanus (20 $\mathrm{Hz})$. Post-tetanus responses to the 50 msec trains were depressed. $B$, Sensory response to a 50 -msec-duration gap within an ongoing $20 \mathrm{~Hz}$ stimulus (ampullary) is shown. Responses to the gap (lowfrequency component) were more than two times greater than that to the ongoing $20 \mathrm{~Hz}$ stimulus. $C$, At $-0.1 \mathrm{nA}$ holding current, active membrane properties further enhanced the response to the lowfrequency component. short train of pulses $(9-10$ pulses at $100 \mathrm{~Hz})$, despite the induction of synaptic depression by a tetanus $(20 \mathrm{~Hz})$.

\section{Utility of synaptic depression for temporal filtering \\ Synaptic processes}

Extracting information concerning slow changes in signal amplitude and rejecting that from fast fluctuations, i.e., low-pass temporal filtering, are fundamental to the utility of the jamming avoidance response (see introductory remarks). Synaptic depression might reduce responses to fast, repetitive patterns of afferent activity while maintaining sensitivity to changes in firing rate (for review, see Abbott et al., 1997; O'Donovan and Rinzel, 1997; Tsodyks and Markram, 1997).

If synaptic depression, triggered by sustained fast temporal stimuli, prevents neurons from responding to low temporal-frequency information, the low-pass filtering function would be defeated. Neurons that had predominantly slow-type PSPs showed facilitating responses to $5 \mathrm{~Hz}$-like trains $(9-10$ pulses at $100 \mathrm{~Hz}$ ) that followed the tetanus $(20 \mathrm{~Hz})$. Active membrane properties often provided further amplification of post-tetanus responses, particularly with levels of current clamp of $-0.1 \mathrm{nA}$ or less.

Synaptic depression, therefore, does not necessarily preclude responses of normal amplitude to particular, biologically relevant temporal patterns of stimulation. After the induction of synaptic depression, PSPs elicited by the fourth or fifth pulses in pulse trains (9-10 pulses at $100 \mathrm{~Hz}$ ) were substantially larger than those to the first or second. The time course of this process is characteristic of classical facilitation and could be triggered by increases in presynaptic calcium (Zucker, 1999). Indeed, in cerebellar slices, facilitation at synapses of parallel fibers onto Purkinje cells stems from processes that depend on residual intracellular $\mathrm{Ca}^{+2}$ levels (Kreitzer and Regehr, 2000). The frequency dependence of $\mathrm{Ca}^{+2}$ buildup then appears to set the stage for depression and facilitation to mediate temporal filtering (Dittman et al., 2000). Postsynaptic mechanisms for enhancement of responses to particular temporal patterns, however, may also be possible. Batchelor and Garthwaite (1997) found that transmission at parallel fiber synapses was enhanced by temporal patterns of stimulation such as those that elicited enhancement of PSP amplitude in the present study (e.g., 5-6 pulses at $100 \mathrm{~Hz}$ ). This frequency-dependent enhancement was specific to the slow PSPs that resulted from activation of metabotropic glutamate receptors and was dependent on postsynaptic $\mathrm{Ca}^{+2}$.

\section{Network processes}

A few neurons showed low-pass filtering to sensory stimulation beyond that expected from passive filtering and PSP depression (see Fig. 2). Extreme cases failed to respond to even the onset of a sensory stimulus of $20 \mathrm{~Hz}$. Most of the cells of this type were found in just two fish. These cells may have received afferents from the centromedial map of the ELL; of the three somatotopic maps in the ELL, only the centromedial region appears specialized for low-pass temporal selectivity (Shumway, 1989). Because pyramidal neurons in the three maps of the ELL convergently project onto the torus, most toral cells may receive input from a constellation of afferents from the three maps, thereby "blurring" the temporal filtering channels.

This idea is supported by the fact that toral processes (passive and active membrane properties and synaptic depression) account for the low-pass filtering properties of most neurons in this region. Frequency-dependent synaptic depression serves to attenuate steady-state activity among toral afferents that are active in response to sensory stimuli of $20 \mathrm{~Hz}$ (either $20 \mathrm{~Hz}$ beat rate or $20 \mathrm{~Hz}$ sinusoid). Because afferents from the centromedial map tend to be low-pass, they should incur less synaptic depression at this stimulus frequency.

This heterogeneity of input may account for the finding that most toral cells responded well to low temporal-frequency elements that were embedded in an otherwise continuous sensory stimulus of $20 \mathrm{~Hz}$ (Rose and Fortune, 1999) (this paper). This "transmission" was observed even for cases in which synaptic depression, induced by the tetanus $(20 \mathrm{~Hz})$, appreciably attenuated responses to short trains (5-10 pulses at $100 \mathrm{~Hz}$ ). This constitutes, therefore, a network-level basis for the sensitivity of toral neurons to low temporal-frequency information in the presence of high temporalfrequency (jamming) input.

Thus, both synaptic and network properties contribute to the transmission of low temporal-frequency information in a background of synaptic depression. These factors help account for the finding that superimposing a fast beat pattern (amplitude modulation) on a slower pattern generally failed to diminish a neuron's response to the slower component (Rose et al., 1994).

\section{Relation to motion detection}

It appears paradoxical that synaptic depression is used for generating low-pass temporal selectivity, because its function appears to be to counteract the consequences of convergence of different streams of temporal information in the torus. It is likely that synaptic depression is important for more than just low-pass temporal filtering. Specifically, synaptic depression may be important in computing the direction of motion of an electric image. Studies of the visual cortex support the link between synaptic depression and directional selectivity (Reid et al., 1991; Jagadeesh et al., 1993). Synaptic depression may create the temporal phase shifts of inputs required by coincidence models of directional selectivity (Chance et al., 1998). Temporal phase shifts in PSP peaks can be seen in Figure 2D.

\section{Diversity of PSP types}

Differences in the PSP time course may account for differences across cells with regard to the temporal summation of consecutive PSPs, particularly during the initial 100-200 msec of each sensory stimulus burst (Rose and Fortune, 1999). In some neurons, pairs of pulses presented in isolation elicited PSPs that had very slow decay phases (as much as $\sim 150 \mathrm{msec}$ ). PSPs with comparably slow decay phases have been recorded, in vitro, from pyramidal cells in the ELL in response to stimulation of the tractus stratum fibrosum (Berman et al., 1997). The late component of these PSPs was mediated by NMDA receptors. NMDA receptors are in moderate density in the torus (Bottai et al., 1997) and may be responsible for the slow-type PSPs. 


\section{Mechanism of synaptic depression and further functional considerations}

In cortical circuits the magnitude of synaptic depression is correlated with the size of initial EPSPs elicited by stimulation (Markram and Tsodyks, 1996); factors that increase release probability give rise to more pronounced depression. As a consequence, for different strengths of stimulation, the steady-state amplitudes of EPSPs are often more similar than are their initial amplitudes; i.e., synaptic depression provides gain control (Abbott et al., 1997). Evidence consistent with this gain control hypothesis can be seen in comparing initial versus steady-state amplitudes of PSPs for different duty cycles of lateral lemniscal stimulation (Fig. 3).

Consistent with studies of synaptic depression in the visual cortex (Varela et al., 1997), the initial phase of depression was followed by a slower depressive phase that had a time constant of $\sim 4 \mathrm{sec}$. The initial phase most likely results from a depletion of the pool of readily releasable quanta of transmitter, because of insufficient replenishment (for review, see Zucker, 1989, 1999; Glavinovic, 1991; O'Donovan and Rinzel, 1997). The readily releasable pool may correspond to the subpopulation of release sites that are emptied by a particular stimulus. Depression may reflect the property that these sites are then temporarily refractory to further release (Dittman et al., 2000). The second, slower phase of depression (time constant of several seconds) may be governed by the time course of replenishment of the readily releasable store of transmitter. One would expect, therefore, that the particular time course of depression would be a function of the strength and duration of stimulation, coupled with the duration of the recovery period between successive stimulation periods. A gap of $\sim 100-200$ msec in an ongoing sensory stimulus was generally sufficient for recovery of the amplitude of the initial EPSP (Rose and Fortune, 1999). For these short recovery times, however, PSP amplitude depressed faster than when much longer gaps were used. Such dependency has also been observed for depression of EPSPs in cortical neurons, in which the initial PSP amplitude and time course of depression are identified with the concepts "synaptic efficacy" and "synaptic reserve," respectively (Galarreta and Hestrin, 1998).

Finally, although our data are consistent with the "depletion" model of synaptic depression, other mechanisms, involving inhibition, are also possible. Postsynaptic inhibition is unlikely, because hyperpolarization failed to alter the pattern or magnitudes of PSP depression. We cannot, however, exclude presynaptic inhibition (Yawo and Chuhma, 1993; Wu and Saggau, 1997).

\section{REFERENCES}

Abbott LF, Varela JA, Sen K, Nelson SB (1997) Synaptic depression and cortical gain control. Science 275:220-224.

Bastian J (1998) Modulation of calcium-dependent postsynaptic depression contributes to an adaptive sensory filter. J Neurophysiol 80:3352-3355.

Batchelor AM, Garthwaite J (1997) Frequency detection and temporally dispersed synaptic signal association through a metabotropic glutamate receptor pathway. Nature 385:74-77.

Berman NJ, Plant J, Turner RW, Maler L (1997) Excitatory amino acid receptors at a feedback pathway in the electrosensory system: implications for the searchlight hypothesis. J Neurophysiol 78:1869-1881.

Bottai D, Dunn RJ, Ellis W, Maler L (1997) $N$-methyl-D-aspartate receptor 1 mRNA distribution in the central nervous system of the weakly electric fish Apteronotus leptorhynchus. J Comp Neurol 389:65-80.

Carr CE, Maler L (1986) Electroreception in gymnotiform fish: central anatomy and physiology. In: Electroreception (Bullock TH, Heiligenberg W, eds), pp 319-324. New York: Wiley.
Castellucci VF, Kandel ER (1974) A quantal analysis of the synaptic depression underlying habituation of the gill-withdrawal reflex of Aplysia. Proc Natl Acad Sci USA 71:5004-5008.

Chance FS, Nelson SB, Abbott LF (1998) Synaptic depression and the temporal response characteristics of V1 cells. J Neurosci 18:4785-4799.

Dittman JS, Kreitzer AC, Regehr WG (2000) Interplay between facilitation, depression, and residual calcium at three presynaptic terminals. J Neurosci 20:1374-1385.

Fortune ES, Rose GJ (1997a) Temporal filtering properties of ampullary electrosensory neurons in the torus semicircularis of Eigenmannia: evolutionary and computational implications. Brain Behav Evol 49:312-323.

Fortune ES, Rose GJ (1997b) Passive and active membrane properties contribute to the temporal filtering properties of midbrain neurons, in vivo. J Neurosci 17:3815-3825.

Galarreta M, Hestrin S (1998) Frequency-dependent synaptic depression and the balance of excitation and inhibition in the neocortex. Nat Neurosci 1:587-594.

Glavinovic MI (1991) Origin of synaptic depression. Periodicum Biologorum 93:519-524.

Heiligenberg W, Rose GJ (1985) Phase and amplitude computations in the midbrain of an electric fish: intracellular studies of neurons participating in the jamming avoidance response of Eigenmannia. J Neurosci 5:515-531.

Jagadeesh B, Wheat HS, Ferster D (1993) Linearity of summation of synaptic potentials underlying direction selectivity in simple cells of the cat visual cortex. Science 262:1901-1904.

Kreitzer AC, Regehr WG (2000) Modulation of transmission during trains at a cerebellar synapse. J Neurosci 20:1348-1357.

Lisman JE (1997) Bursts as a unit of neural information: making unreliable synapses reliable. Trends Neurosci 20:38-43.

Markram H, Tsodyks MV (1996) Redistribution of synaptic efficacy between neocortical pyramidal neurons. Nature 382:807-810.

O'Donovan MJ, Rinzel J (1997) Synaptic depression: a dynamic regulator of synaptic communication with varied functional roles. Trends Neurosci 20:431-433.

Partridge BL, Heiligenberg W, Matsubara J (1981) The neural basis for a sensory filter in the jamming avoidance response: no grandmother cells in sight. J Comp Physiol [A] 145:153-168.

Reid RC, Soodak RE, Shapley RM (1991) Direction selectivity and spatiotemporal structure of receptive fields of simple cells in cat striate cortex. J Neurophysiol 66:505-529.

Rose GJ, Call SJ (1993) Temporal filtering properties of neurons in the midbrain of an electric fish: implications for the function of dendritic spines. J Neurosci 13:1178-1189.

Rose GJ, Fortune ES (1996) New techniques for making whole-cell recordings from CNS neurons in vivo. Neurosci Res 26:89-94.

Rose GJ, Fortune ES (1999) Frequency-dependent PSP depression contributes to low-pass temporal filtering in Eigenmannia. J Neurosci 19:7629-7639.

Rose GJ, Etter N, Alder TB (1994) Responses of electrosensory neurons in the torus semicircularis of Eigenmannia to complex beat stimuli: testing hypotheses of temporal filtering. J Comp Physiol [A] 175:467-474.

Shumway C (1989) Multiple electrosensory maps in the medulla of weakly electric gymnotiform fish. I. Physiological differences. J Neurosci 9:4388-4399.

Tsodyks MV, Markram H (1997) The neural code between neocortical pyramidal neurons depends on neurotransmitter release probability. Proc Natl Acad Sci USA 94:719-723.

Varela JA, Sen K, Gibson J, Frost J, Abbott LF, Nelson SB (1997) A quantitative description of short-term plasticity at excitatory synapses in layer 2/3 of rat primary visual cortex. J Neurosci 17:7926-7940.

Wu LG, Saggau P (1997) Presynaptic inhibition of elicited neurotransmitter release. Trends Neurosci 20:204-212.

Yawo H, Chuhma N (1993) Preferential inhibition of $\omega$-conotoxinsensitive presynaptic $\mathrm{Ca}^{+2}$ channels by adenosine autoreceptors. Nature 365:256-258.

Zador A, Dobrunz L (1997) Dynamic synapses in the cortex. Neuron 19:1-4.

Zucker RS (1989) Short-term synaptic plasticity. Annu Rev Neurosci 12:13-31.

Zucker RS (1999) Calcium- and activity-dependent synaptic plasticity. Curr Opin Neurobiol 9:305-313. 